\title{
Diagnosis and Management of ED
}

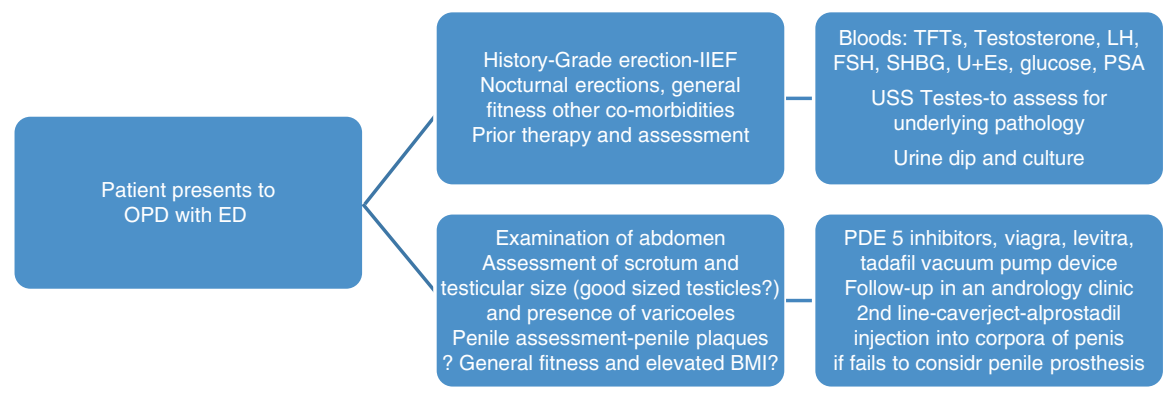

\section{Suggested Reading}

Banks E, Joshy G, Abhayaratna WP, Kritharides L, Macdonald PS, Korda RJ, Chalmers JP. Erectile dysfunction severity as a risk marker for cardiovascular disease hospitalisation and all-cause mortality: a prospective cohort study. PLoS Med. 2013;10(1):e1001372.

Pastuszak AW. Current diagnosis and management of erectile dysfunction. Curr Sex Health Rep. 2014;6(3):164-76.

Yafi FA, Jenkins L, Albersen M, Corona G, Isidori AM, Goldfarb S, Maggi M, Nelson CJ, Parish S, Salonia A, Tan R, Mulhall JP, Hellstrom WJG. Erectile dysfunction. Nat Rev Dis Primers. 2016;2:16003. 